\title{
BILATERAL INTRAOCULAR HAEMORRHAGE: RARE AND ONLY MANIFESTATION OF DENGUE FEVER
}

Ramamurthy P1, Venugopal K², Lingaraja Mudegoudara ${ }^{3}$, Kushal D. P4, Manjunath Ganiger ${ }^{5}$

\author{
HOW TO CITE THIS ARTICLE: \\ Ramamurthy P, Venugopal K, Lingaraja Mudegoudara, Kushal D. P, Manjunath Ganiger. "Bilateral Intraocular \\ Haemorrhage: Rare and only Manifestation of Dengue Fever". Journal of Evolution of Medical and Dental \\ Sciences 2014; Vol. 3, Issue 53, October 16; Page: 12382-12385, DOI: 10.14260/jemds/2014/3638
}

\begin{abstract}
Dengue fever is caused by dengue virus of Flavivirus family transmitted by Aedes aegypti. It causes acute febrile illness with various constitutional symptoms with bleeding manifestations and shock in some instances. Ocular involvement has been reported frequently. Most common ocular symptoms include intra-retinal haemorrhages, macular haemorrhages, Roth's spot, cotton wool spot and disc edema. However, bilateral intra vitreal hemorrhage with permanent visual loss is very rare has been rarely reported. Here we report a case of 27 year male patient presented with fever of seven days, retro-orbital pain, headache, backache and myalgia. Over next few days he developed severe bilateral intra-vitreal hemorrhage. Patient treated for intra-ocular bleeding and unfortunately without regaining his visual function.
\end{abstract}

KEYWORDS: dengue fever, intra-ocular haemorrhage, ocular manifestations.

INTRODUCTION: Dengue fever also known as break bone fever is caused by dengue virus. It is an RNA virus of the family Flaviviridae. It is transmitted by Aedes aegypti. It causes symptoms like fever, headache, muscle pain, back pain, joint pain and other constitutional symptoms. In small proportion of patients it produces dengue hemorrhagic fever characterized by capillary leak, low platelet count and bleeding manifestations and dengue shock syndrome is characterised by hypotension. Most life threatening complication of dengue includes acute respiratory distress syndrome. Dengue can produces various ocular complications ranges from blurring of vision to permanent visual loss. Most of the ocular symptoms resolve spontaneously without any treatment in two to three weeks. Severe permanent visual loss is unusual and has been rarely reported in the literature.

CASE REPORT: A 27 year old male patient presented to the medicine outpatient department of our hospital with history of fever since one week. Fever was not associated with chills; it was intermittent, moderate grade, associated with four episodes of vomiting. Vomitus contains food particle. He also gave history of retro-orbital pain, myalgia, headache and backache. There was no bleeding manifestation at the time of admission. His pulse rate was 86 per minute, blood pressure was $110 / 70 \mathrm{mmh}$ and his respiratory rate was 20 per minute. Systemic examination was normal except for right hypochondriac tenderness and mild hepatomegaly.

Complete hemogram showed total leukocyte count of 3200 cells/cumm, red cell count of 4 million, hemoglobin of $12.8 \mathrm{gm} \%$ and platelet count of 32,000cells/cumm. He was positive for dengue NS1 antigen and IgM antibody. His peripheral smear for malaria, Widal test for typhoid was negative. His renal parameters, liver parameters and electrolytes were within normal limits. Urine routine was normal. Patient initially managed with intravenous saline and paracetamol for fever. Next day, patient developed subconjunctival hemorrhage with diminished vision. 
In view of decreased platelet count and increased hematocrit, patient was transfused with four point platelets. Patient's platelet count was 18,000cells/cumm. Next day, patient developed bilateral swollen eyes with intraocular haemorrhage (FIGURE-1). Ultrasound of the eyes demonstrated intraocular haemorrhage. His brain's CT scan was normal (FIGURE-2). Patient referred to ophthalmology for the management of intraocular haemorrhage. Aspiration of the blood and vitrectomy was done; patient was given five points of fresh whole blood and eight points of platelets. On day-5, patients bleeding stopped with improvement of platelet count without improvement of visual function.

DISCUSSION: Flaviviruses are icosahedral nucleocapsids surrounded by an envelope and a singlestranded, positive-polarity RNA genome. The virus measures 40 to $50 \mathrm{~nm}$ in diameter. There are 4 serotypes of dengue virus that cause a wide spectrum of clinical disease ranging from asymptomatic infection to dengue hemorrhagic fever. The most common clinical manifestation of dengue is dengue fever. While dengue hemorrhagic fever occurs in a minority of patients and is characterized by the leakage of plasma. Dengue is endemic in this part of north Karnataka. Many patients are from Bengali camp, where they are working in the rice fields.

Most of the cases occur in the summer months of June, July, and August. Fever is the most common feature of the disease followed by generalized muscle aches, headaches, and vomiting. The main hematological abnormalities are thrombocytopenia and leukopenia. Ocular involvement in dengue fever has been reported in many studies. Subconjunctival petechial haemorrhage, secondary to marked thrombocytopenia, is the most common ocular involvement as reported in an East Indian population. ${ }^{[1]}$ However, patients may present during recovery phase i.e. one week after the onset of fever with a sudden loss of vision or a central scotoma.

These manifestations are due to involvement of the retinal and/or choroidal circulation, with a predilection for the macular area. The main findings of dengue maculopathy are retinal hemorrhage, venular sheathing, yellow subretinal dots, retinal pigment epithelium mottling, foveolitis, disc hyperemia and disc edema. Neurosensory retinal detachment is seen in $15 \%$ of eyes with retinal vascular leakage.[2] Optic neuritis is another important ocular involvement in patients of dengue fever, which may be unilateral or bilateral.[3]

However bilateral vitreous haemorrhage is the rare manifestation of dengue fever and very rarely has been reported. ${ }^{[4]}$ Hence, we hereby report a case of dengue fever causing bilateral vitreous haemorrhage and loss of vision in both eyes.

\section{REFERENCES:}

1. Kapoor HK, Bhai S, John M, Xavier J. Ocular manifestations of dengue fever in an East Indian epidemic. Can J Ophthalmol 2006; 41: 741-6.

2. Khairallah M, Jelliti B, Jenzeri S. Emergent infectious uveitis. Middle East Afr J Ophthalmol 2008; 16: 225-38.

3. Mohindra VK, Kumari A. Unilateral optic neuritis associated with dengue fever. DJO 2013; 23 : 289-91.

4. S Nainiwal, S P Garg, G Prakash, N Nainiwal. Bilateral vitreous haemorrhage associated with dengue fever. Eye 2005; 19: 1012-13. 


\section{CASE REPORT}

IMAGE 1: bilateral swollen eyeballs due to intra-ocular haemorrhage.

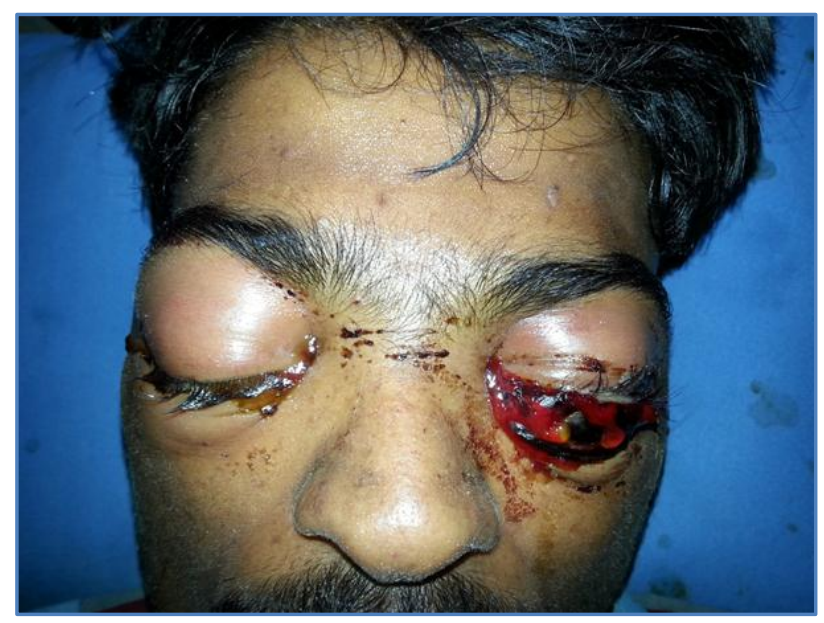

Image 1

IMAGE 2: CT brain plain showing intra-ocular haemorrhage without any evidence of retro orbital haemorrhage.

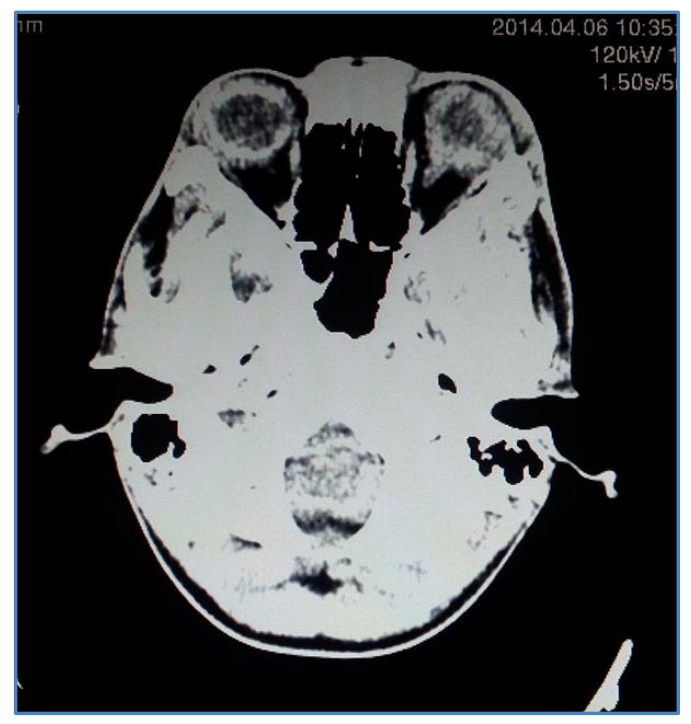

Image 2 


\section{AUTHORS:}

1. Ramamurthy P.

2. Venugopal K.

3. Lingaraja Mudegoudara

4. Kushal D. P.

5. Manjunath Ganiger

\section{PARTICULARS OF CONTRIBUTORS:}

1. Associate Professor, Department of General Medicine, VIMS, Bellary.

2. Post Graduate, Department of General Medicine, VIMS, Bellary.

3. Post Graduate, Department of General Medicine, VIMS, Bellary.

4. Post Graduate, Department of General Medicine, VIMS, Bellary.
5. Post Graduate, Department of General Medicine, VIMS, Bellary.

\section{NAME ADDRESS EMAIL ID OF THE} CORRESPONDING AUTHOR:

Dr. Ramamurthy P, Associate Professor, Vijayanagara Institute of Medical Sciences, Bellary-583104.

Email: ramamurthypujar@gmail.com

Date of Submission: 24/09/2014. Date of Peer Review: 25/09/2014. Date of Acceptance: 11/10/2014. Date of Publishing: 16/10/2014. 